\title{
Strategies to improve treatment outcome in gastric cancer: A retrospective analysis of patients from two high-volume hospitals in Korea and China
}

\author{
Kun Yang ${ }^{1,2,3,4, *}$, Yoon Young Choi ${ }^{3, *}$, Wei-Han Zhang ${ }^{1,2}$, Xin-Zu Chen ${ }^{1,2}$, Mi Kyung \\ Song ${ }^{5}$, Jinae Lee ${ }^{5}$, Bo Zhang ${ }^{1}$, Zhi-Xin Chen ${ }^{1}$, Hyoung-Il Kim ${ }^{3,4}$, Jia-Ping Chen ${ }^{1}$, Jae-Ho \\ Cheong ${ }^{3}$, Zong-Guang Zhou ${ }^{1}$, Woo Jin Hyung ${ }^{3,4}$, Jian-Kun $\mathrm{Hu}^{1,2}$, Sung Hoon $\mathrm{Noh}^{3}$ \\ ${ }^{1}$ Department of Gastrointestinal Surgery, West China Hospital, Sichuan University, Chengdu, China \\ ${ }^{2}$ Laboratory of Gastric Cancer, State Key Laboratory of Biotherapy, West China Hospital, Sichuan University, Chengdu, China \\ ${ }^{3}$ Department of Surgery, Severance Hospital, Yonsei University Health System, Yonsei University College of Medicine, Seoul, \\ Republic of Korea \\ ${ }^{4}$ Robot and Minimal Invasive Surgery Center, Severance Hospital, Yonsei University Health System, Seoul, Republic of Korea \\ ${ }^{5}$ Biostatistics Collaboration Unit, Yonsei University College of Medicine, Seoul, Republic of Korea \\ *Co-first authors \\ Correspondence to: Sung Hoon Noh, email: sunghoonn@yuhs.ac \\ Jian-Kun Hu, email: hujkwch@126.com
}

Keywords: gastric cancer, gastrectomy, tumour characteristics, D2 lymphadenectomy, chemotherapy

Received: December 03, 2015

Accepted: April 23, 2016

Published: May 15, 2016

\section{ABSTRACT}

China has high incidence of gastric cancer (GC). However, the treatment outcomes of China were unsatisfactory compared to those of Korea. We performed this study to compare tumour characteristics, treatment parameters, and survival outcomes of GC patients between Korea and China based on the databases of two high-volume hospitals, with the aim of identifying indicators of GC prognosis. Data of patients undergoing gastrectomy for GC from 2006 to $\mathbf{2 0 1 0}$ were analysed retrospectively. Subgroup survival analyses, stratified by clinicopathologic factors and multivariable analyses, were performed. The interactive roles of chemotherapy and D2 lymphadenectomy for overall survival were also investigated. Among 1365 Chinese and 4981 Korean patients, the proportion of early cancer detection in Chinese patients was much lower relative to that of Korean patients. There were no significant differences between countries in terms of surgical morbidity and mortality. The overall 5-year survival rates were $54.3 \%$ and $81.4 \%$; when stratified by clinicopathologic factors, the survival were generally statistically higher in Korean patients. Gender, age, T stage, $\mathbf{N}$ stage, extent of lymphadenectomy, radicality of surgery, resection type, and chemotherapy were independently associated with survival in patients without metastasis. Survival rates for stage II and III GC differed significantly between the two countries, but this difference was eliminated among patients who underwent D2 lymphadenectomy or received chemotherapy. These treatments were given to patients with advancedstage diagnoses (approximately $20 \%$ and $80 \%$ of patients, respectively). Treatment type was selected as independent prognostic factors in stage I-III and D2/D2+, with chemotherapy resulting in the best prognosis. Many differences in GC tumour characteristics exist between two countries. Early cancer detection and standardized treatment in Korea contribute to superior survival rates. Promotion of an early screening program, training and dissemination of standard D2 lymphadenectomy, and appropriate applications of chemotherapy would improve survival outcomes. 


\section{INTRODUCTION}

The overall incidence of gastric cancer (GC) has been decreasing globally in recent years; however, it remains a disease with high incidence and mortality in East Asian countries [1]. China has a particularly high incidence of GC, accounting for nearly $45 \%$ of new GC cases and $40 \%$ of GC-related deaths worldwide $[1,2]$. Compared with Korea, the long-term survival rates of GC patients, especially when diagnosed in advanced stages, are still not satisfactory in China, although they have improved in recent years. Despite the fact that GC is the most common cancer in Korea, its 5-year overall survival rates have been approximately $70 \%$ in recent years [3]. The reasons accounting for the survival differences between these two countries remain unclear and should be explored further. Furthermore, unsatisfactory treatment outcomes urge us to find effective strategies for treating $\mathrm{GC}$ in China. Considering the huge number of Chinese GC cases, improving treatment would significantly impact patients' survival.

The survival rates after curative gastrectomy for GC is higher in East Asian countries than in Western countries [4-7]. Therefore, some studies have promoted the treatment of GC by comparing East Asian with Western countries. Because differences exist in intrinsic biological factors, diagnosis, and treatment of GC between Eastern and Western countries [4, 8, 9], some findings from Western countries have limitations when applied to China. However, Korean populations have similarities to Chinese populations in environment, genetic susceptibility to GC, and application of surgical procedures. Consequently, comparing Korea and China may be more meaningful than comparing Western and East Asian countries.

Therefore, we compared tumour characteristics, treatment parameters, and survival outcomes of GC patients between Korea and China based on the databases of two high-volume hospitals, with the aim of identifying factors that improve GC prognosis. To our knowledge, this is the first study to directly compare the characteristics and treatment outcomes of GC between Korea and China.

\section{RESULTS}

\section{Clinicopathologic characteristics of patients}

Clinicopathologic characteristics of patients are summarised in Table 1. The proportion of female patients in Korea was slightly higher than in Chinese patients. The percentage of patients with comorbidities was higher in Chinese patients. The locations of tumours were statistically different between these two countries. In Chinese patients, differentiation was poorer, tumours larger, depth of invasion greater, rate of lymph node involvement higher, and advanced stages more frequent relative to Korean patients. Distant metastasis was also more frequent in Chinese patients. The percentage of early GC (pT1, EGC) in Korean patients was much higher than that of Chinese patients. More Korean than Chinese patients were node-negative.

\section{Treatment outcomes}

Treatment outcomes are summarised in Table 2. A higher percentage of minimally invasive surgery, including laparoscopic surgery and robotic surgery, was conducted in Korea than China. Resection type differed significantly between countries, with distal gastrectomies performed more frequently in Korean patients and non-curative resections performed more frequently in Chinese patients. Lymphadenectomy approach also differed significantly between the countries. D1/D1 ${ }^{+}$ lymphadenectomy was performed more often in Chinese than Korean patients; the reverse was true of D2/D2+ lymphadenectomy. The mean number of harvested lymph nodes was significantly lower in Chinese patients, not only overall, but also among patients who received a D2/D2+ lymphadenectomy. However, the overall postoperative morbidity rates and mortality were not significantly different between these two countries. Neo-adjuvant chemotherapy was rarely performed in both countries. Adjuvant treatment differed significantly between Chinese and Korean patients.

\section{Prognosis of GC}

The 5-year OS for Chinese and Korean patients was $54.3 \%$ and $81.4 \%$, respectively $(P<0.001$, Figure $1 \mathrm{~A})$. When stratified by clinicopathologic characteristics and treatment parameters, the prognoses of Korean patients were substantially better than those of Chinese patients in most subgroup analyses; in advanced GC subgroups, such as those receiving $\mathrm{R} 1 / \mathrm{R} 2$ resection, whole stomach lesion, T4b, N3b, or with distant metastasis, the OS of Chinese patients was not significantly different from that of Korean patients (Table 3). Prognosis was also compared between countries according to stage, and OS was significantly lower among Chinese stage II and III patients (Table 3 and Figure 1B-1E).

\section{Independent prognostic factors}

Because the prognoses differed in Chinese and Korean patients, even for patients in the same TNM stages (especially for stage II and III), further analyses focused on identifying independent prognostic factors in overall. The analysis classified patients into two groups: those without distant metastasis (M0) and those with metastasis (M1). In M0 patients, gender, age, depth of infiltration, nodal status, extent of lymphadenectomy, radicality of surgery, resection type, and chemotherapy were independently associated with prognosis (Table 4). 
Table 1: General clinicopathological characteristics of the patients between different countries

\begin{tabular}{|c|c|c|c|}
\hline & $\begin{array}{c}\text { China } \\
(N=1365)^{*}\end{array}$ & $\begin{array}{c}\text { Korea } \\
(N=4981)^{*}\end{array}$ & $P$ value \\
\hline Gender & & & 0.001 \\
\hline Female & $409(30.0)$ & 1737 (34.9) & \\
\hline Male & $956(70.0)$ & $3244(65.1)$ & \\
\hline Age (yrs) & & & 0.118 \\
\hline$<60$ & $768(56.3)$ & 2684 (53.9) & \\
\hline$\geq 60$ & $597(43.7)$ & $2297(46.1)$ & \\
\hline Comorbidity & $738(54.1)$ & $2427(48.7)$ & $<0.001$ \\
\hline Tumor location & & & $<0.001$ \\
\hline Upper third & $349(25.6)$ & $681(13.7)$ & \\
\hline Middle third & $180(13.2)$ & $1365(27.4)$ & \\
\hline Lower third & $806(59.1)$ & $2919(58.6)$ & \\
\hline Whole stomach & $30(2.2)$ & $16(0.3)$ & \\
\hline Differentiation & & & $<0.001$ \\
\hline G1 & $15(1.1)$ & $652(13.1)$ & \\
\hline $\mathrm{G} 2$ & $180(13.2)$ & $1415(28.4)$ & \\
\hline G3 & $1170(85.7)$ & $2914(58.5)$ & \\
\hline Tumor size $(\mathrm{cm})$ & & & $<0.001$ \\
\hline$\leq 2$ & $200(14.7)$ & $1665(33.4)$ & \\
\hline$\sim 5.0$ & $645(47.3)$ & $2277(45.7)$ & \\
\hline$\sim 8.0$ & 399 (29.2) & $756(15.2)$ & \\
\hline$>8.0$ & $121(8.9)$ & $283(5.7)$ & \\
\hline Depth of infiltration (pT) & & & $<0.001$ \\
\hline pT1 & $231(16.9)$ & $2713(54.5)$ & \\
\hline pT2 & $172(12.6)$ & $555(11.1)$ & \\
\hline pT3 & $85(6.2)$ & $649(13.0)$ & \\
\hline pT4a & $716(52.5)$ & $1031(20.7)$ & \\
\hline pT4b & $161(11.8)$ & $33(0.7)$ & \\
\hline Nodal status (pN) & & & $<0.001$ \\
\hline pN0 & $412(30.2)$ & $3124(62.7)$ & \\
\hline $\mathrm{pN} 1$ & $245(18.0)$ & $605(12.2)$ & \\
\hline $\mathrm{pN} 2$ & $222(16.3)$ & $514(10.3)$ & \\
\hline $\mathrm{pN} 3 \mathrm{a}$ & $302(22.1)$ & $457(9.2)$ & \\
\hline $\mathrm{pN} 3 \mathrm{~b}$ & $184(13.5)$ & $281(5.6)$ & \\
\hline Distal metastasis (M) & & & $<0.001$ \\
\hline M0 & $1221(89.5)$ & $4837(97.1)$ & \\
\hline M1 & $144(10.6)$ & $144(2.9)$ & \\
\hline Stage & & & $<0.001$ \\
\hline I & $281(20.6)$ & $2931(58.8)$ & \\
\hline II & $264(19.3)$ & $797(16.0)$ & \\
\hline III & $676(49.5)$ & $1109(22.3)$ & \\
\hline IV & $144(10.6)$ & $144(2.9)$ & \\
\hline
\end{tabular}

*Frequency (percentage).

In M1 patients, tumour size and chemotherapy were independent prognostic factors. Among these independent prognostic factors, lymphadenectomy and chemotherapy were the only clinically-correctable factors; thus, we extended our analysis to compare prognoses in patients who underwent D2/D2+ lymphadenectomy (Figure 2A-2D) or received adjuvant chemotherapy (Figure 3A-3C). Intriguingly, the prognostic differences between Chinese and Korean patients were attenuated when D2/D2+ lymphadenectomy and chemotherapy were analysed 
Table 2: Details of treatment and surgical short-term outcomes between different countries

\begin{tabular}{|c|c|c|c|}
\hline & $\begin{array}{c}\text { China } \\
(N=\mathbf{1 3 6 5})^{\dagger}\end{array}$ & $\begin{array}{c}\text { Korea } \\
(N=\mathbf{4 9 8 1})^{\dagger}\end{array}$ & $P$ value \\
\hline Surgical methods & & & $<0.001$ \\
\hline Open surgery & $1176(86.2)$ & $3773(75.8)$ & \\
\hline Laparoscopic surgery & $189(13.9)$ & $779(15.6)$ & \\
\hline Robotic surgery & $0(0)$ & $429(8.6)$ & \\
\hline Resection type & & & $<0.001$ \\
\hline Distal gastrectomy & $793(58.1)$ & $3660(73.5)$ & \\
\hline Proximal gastrectomy & $230(16.9)$ & $0(0)$ & \\
\hline Total gastrectomy & $342(25.1)$ & $1321(26.5)$ & \\
\hline Lymphadenectomy & & & 0.004 \\
\hline D1/ D1+ & $689(50.5)$ & $2294(46.1)$ & \\
\hline $\mathrm{D} 2 / \mathrm{D} 2+*$ & $676(49.5)$ & $2687(53.9)$ & \\
\hline Radicality of surgery & & & $<0.001$ \\
\hline R0 & $1239(90.8)$ & $4780(96.0)$ & \\
\hline $\mathrm{R} 1 / \mathrm{R} 2$ & $126(9.2)$ & $201(4.0)$ & \\
\hline Reconstructions & & & 0.000 \\
\hline Billroth-1 & $192(14.07 \%)$ & $1853(37.20 \%)$ & \\
\hline Billroth-2 & $589(43.15 \%)$ & $1792(35.98 \%)$ & \\
\hline Roux-en-Y & $354(25.93 \%)$ & $1336(26.82 \%)$ & \\
\hline Esophagogastric anastomosis & $230(16.85 \%)$ & $0(0 \%)$ & \\
\hline No. of total harvested lymph nodes & $27.22 \pm 13.01$ & $40.12 \pm 16.03$ & $<0.001$ \\
\hline No. of total harvested lymph nodes in D2 subgroup & $30.00 \pm 12.90$ & $43.42 \pm 16.43$ & $<0.001$ \\
\hline No. of lymph nodes with positive metastasis & $6.43 \pm 8.39$ & $3.07 \pm 7.42$ & $<0.001$ \\
\hline Postoperative hospital stays (day) & $11.41 \pm 7.75$ & $9.79 \pm 9.36$ & 0.000 \\
\hline Estimated blood loss (mL) (4909 patients for analysis) & $172.00 \pm 154.71$ & $120.27 \pm 192.66$ & 0.000 \\
\hline Operation time (min) (5806 patients for analysis) & $242.34 \pm 54.38$ & $169.16 \pm 57.49$ & 0.000 \\
\hline Number of patients with postoperative morbidity & $200(14.7)$ & $708(14.2)$ & 0.682 \\
\hline Clavien-Dindo classification of postoperative morbidity & & & 0.166 \\
\hline $\mathrm{I}$ & $62(4.5)$ & $222(4.5)$ & \\
\hline II & $75(5.5)$ & $240(4.8)$ & \\
\hline IIIa & $42(3.1)$ & $156(3.1)$ & \\
\hline $\mathrm{IIIb}$ & $10(0.7)$ & $70(1.4)$ & \\
\hline $\mathrm{IVa}$ & $3(0.2)$ & $3(0.1)$ & \\
\hline $\mathrm{IVb}$ & $2(0.1)$ & $5(0.1)$ & \\
\hline $\mathrm{V}$ & $6(0.4)$ & $12(0.2)$ & \\
\hline Mortality & $6(0.4)$ & $12(0.2)$ & 0.221 \\
\hline Chemotherapy & & & $<0.001$ \\
\hline No chemotherapy & $764(56.0)$ & $3411(68.5)$ & \\
\hline Neo-adjuvant chemotherapy & $12(0.9)$ & $87(1.7)$ & \\
\hline Adjuvant chemotherapy & $575(42.1)$ & $1408(28.3)$ & \\
\hline Unclear & $14(1.0)$ & $75(1.5)$ & \\
\hline
\end{tabular}

*: D2 included No.14v lymph nodes dissection.

$\dagger$ Frequency (percentage). 
in isolation. Furthermore, country was not selected by multivariable analyses as an independent prognostic factor in either the M0 or M1 group (Table 4).

\section{Effects of lymphadenectomy and chemotherapy by GC stage}

To scrutinize the effects of lymphadenectomy and chemotherapy across all stages, 5-year OS was compared at each stage (Table 5). The benefit of chemotherapy was observed mainly in stage III and IV, and the prognosis of the chemotherapy group was significantly better than the no-chemotherapy group in stage II when D1/D1+ lymphadenectomy was performed. When the benefit of D2/D2+ vs. D1/D1+ lymphadenectomy was compared, the prognosis of the D2/D2+ group was better in stage III, but not stages I, II, or IV. Intriguingly, D2/D2+ lymphadenectomy was positively related to prognosis in stage II when the patients did not receive chemotherapy.

\section{Different treatment in different countries and the possible benefit of D2/D2+ lymphadenectomy and chemotherapy in China}

We assessed the proportions of patients received D2/ D2+ lymphadenectomy and/or chemotherapy, stratifying these independent and clinically-correctable prognostic factors by stage in both countries (Table 6). Approximately $50 \%$ of Chinese patients with advanced disease (stage III and IV) received D2/D2+ lymphadenectomy or chemotherapy, while over $80 \%$ of patients in Korea. Only around $20 \%$ of Chinese patients were treated by both D2/D2+ lymphadenectomy and chemotherapy; but over $60 \%$ of patients in Korea. When comparing the benefit of the combination of D2/D2+ lymphadenectomy and chemotherapy according to each stage in Chinese patients, D1/D1+ lymphadenectomy without chemotherapy in stage II and III had the poorest prognosis, whereas the benefit from D2/D2+ lymphadenectomy with chemotherapy was prominent in stage III (Figure 4A-4D). In multivariable analyses, treatment type was selected as an independent prognostic factor in M0 patients, where D2/D2+ lymphadenectomy with chemotherapy showed the best prognosis (Table 7). Treatment type was also an independent prognostic factor in M1 patients. However, only chemotherapy was positively correlated to better prognosis; D2/D2+ lymphadenectomy was not.

\section{DISCUSSION}

In our analyses, the 5-year OS rate of Korean GC patients was substantially higher than that of Chinese
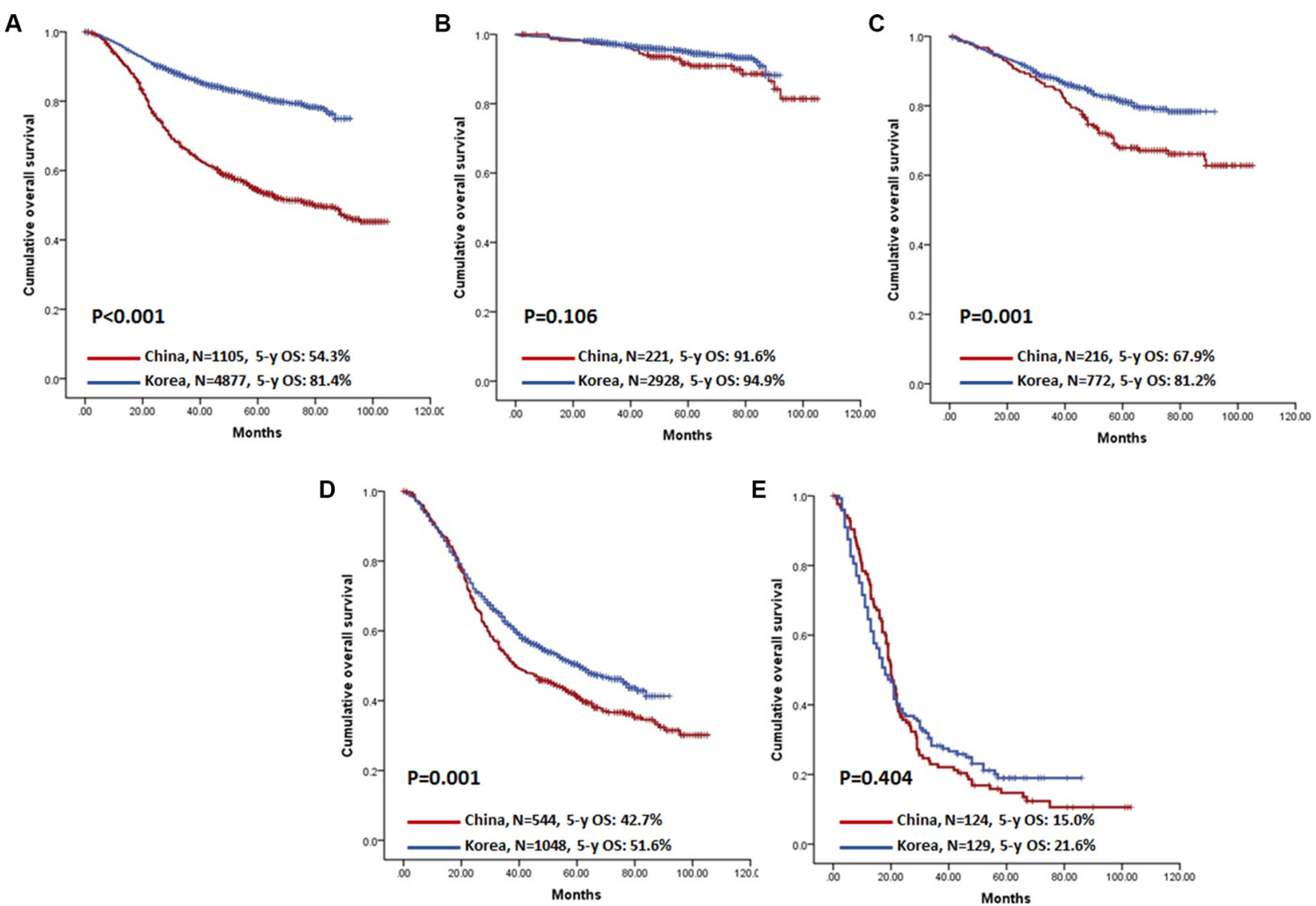

Figure 1: Kaplan-Meier survival analysis of patients between China and Korea. (A) Overall patients. (B-E) Patients stratified by stage. (B) Stage I patients; (C) Stage II patients; (D) Stage III patients; (E) Stage IV patients. 
Table 3: Survival analyses stratified by clinicopathologic characteristics and treatment parameters in different countries

\begin{tabular}{|c|c|c|c|c|c|}
\hline & \multicolumn{2}{|c|}{ China $(N=1105)$} & \multicolumn{2}{|c|}{ Korea $(N=4877)$} & \multirow{2}{*}{$P$ value ${ }^{\dagger}$} \\
\hline & $N$ & 5-y OSR (\%) & $N$ & 5-y OSR (\%) & \\
\hline \multicolumn{6}{|l|}{ Gender } \\
\hline Female & 324 & 56.3 & 1700 & 83.3 & $<0.001$ \\
\hline Male & 781 & 53.4 & 3177 & 80.4 & $<0.001$ \\
\hline \multicolumn{6}{|l|}{ Age (yrs) } \\
\hline$<60$ & 618 & 55.4 & 2643 & 84.5 & $<0.001$ \\
\hline$\geq 60$ & 487 & 52.9 & 2234 & 77.6 & $<0.001$ \\
\hline \multicolumn{6}{|l|}{ Longitudinal Tumor location } \\
\hline Upper third & 280 & 43.7 & 670 & 76.9 & $<0.001$ \\
\hline Middle third & 140 & 54.4 & 1334 & 82.4 & $<0.001$ \\
\hline Lower third & 661 & 59.9 & 2861 & 82.1 & $<0.001$ \\
\hline Whole stomach & 24 & 23.4 & 12 & 43.7 & 0.155 \\
\hline \multicolumn{6}{|l|}{ Differentiation } \\
\hline G1 & 11 & 90.0 & 645 & 92.0 & 0.814 \\
\hline $\mathrm{G} 2$ & 148 & 62.7 & 1387 & 81.0 & $<0.001$ \\
\hline G3 & 946 & 52.6 & 2845 & 79.1 & $<0.001$ \\
\hline \multicolumn{6}{|l|}{ Tumor size (cm) } \\
\hline$\leq 2$ & 157 & 83.8 & 1660 & 94.7 & $<0.001$ \\
\hline$\sim 5.0$ & 523 & 59.2 & 2232 & 83.0 & $<0.001$ \\
\hline$\sim 8.0$ & 327 & 40.0 & 719 & 62.6 & $<0.001$ \\
\hline$>8.0$ & 98 & 28.1 & 266 & 40.3 & 0.026 \\
\hline \multicolumn{6}{|l|}{ Depth of infiltration (pT) } \\
\hline pT1 & 180 & 91.4 & 2710 & 95.0 & 0.056 \\
\hline pT2 & 150 & 71.4 & 547 & 85.0 & 0.001 \\
\hline pT3 & 73 & 54.3 & 621 & 75.3 & $<0.001$ \\
\hline pT4a & 573 & 44.4 & 970 & 47.7 & 0.352 \\
\hline pT4b & 129 & 26.1 & 29 & 23.6 & 0.278 \\
\hline \multicolumn{6}{|l|}{ Nodal status (pN) } \\
\hline $\mathrm{pN} 0$ & 320 & 80.9 & 3111 & 92.8 & $<0.001$ \\
\hline pN1 & 200 & 61.8 & 583 & 84.1 & $<0.001$ \\
\hline pN2 & 184 & 60.1 & 493 & 68.9 & 0.020 \\
\hline pN3a & 245 & 32.8 & 432 & 45.1 & 0.001 \\
\hline $\mathrm{pN} 3 \mathrm{~b}$ & 156 & 16.8 & 258 & 22.9 & 0.249 \\
\hline \multicolumn{6}{|l|}{ Distal metastasis (M) } \\
\hline M0 & 981 & 59.2 & 4748 & 83.0 & $<0.001$ \\
\hline M1 & 124 & 15.0 & 129 & 21.6 & 0.404 \\
\hline \multicolumn{6}{|l|}{ Stage } \\
\hline I & 221 & 91.6 & 2928 & 94.9 & 0.106 \\
\hline II & 216 & 67.9 & 772 & 81.2 & 0.001 \\
\hline III & 544 & 42.7 & 1048 & 51.6 & 0.001 \\
\hline IV & 124 & 15.0 & 129 & 21.6 & 0.404 \\
\hline \multicolumn{6}{|l|}{ Surgical methods } \\
\hline Open surgery & 943 & 52.9 & 3675 & 78.1 & $<0.001$ \\
\hline Minimal invasive surgery & 162 & 62.2 & 1202 & 92.0 & $<0.001$ \\
\hline \multicolumn{6}{|l|}{ Resection type } \\
\hline Subtotal gastrectomy & 827 & 59.1 & 3606 & 86.1 & $<0.001$ \\
\hline Total gastrectomy & 278 & 40.0 & 1271 & 68.0 & $<0.001$ \\
\hline
\end{tabular}




\begin{tabular}{|l|c|c|c|c|c|}
\hline Lymphadenectomy & & & & & \\
\hline D1/ D1+ & 578 & 49.4 & 2278 & 91.3 & $<0.001$ \\
\hline D2/ D2+* & 527 & 59.6 & 2599 & 72.3 & $<0.001$ \\
\hline Radicality of surgery & & & & & \\
\hline R0 & 996 & 58.6 & 4695 & 83.6 & $<0.001$ \\
\hline R1/R2 & 109 & 14.4 & 182 & 25.7 & 0.065 \\
\hline Chemotherapy & & & & & \\
\hline No & 593 & 50.0 & 3396 & 91.5 & $<0.001$ \\
\hline Yes & 512 & 59.2 & 1481 & 57.9 & 0.347 \\
\hline
\end{tabular}

Abbreviations: OSR, overall survival rate.

*: D2 included No.14v lymph nodes dissection.

$\dagger p$-value for log-rank test.

Table 4: The prognostic factors on the univariable and multivariable cox-proportional hazard regression analyses

\begin{tabular}{|c|c|c|c|c|c|c|c|c|}
\hline & \multicolumn{4}{|c|}{ M0 patients $(N=5729)$} & \multicolumn{3}{|c|}{ M1 patients $(N=253)$} & \multirow[b]{2}{*}{$P$ value } \\
\hline & $\begin{array}{c}\text { Univariable HR } \\
(95 \% \mathrm{CI})\end{array}$ & $P$ value & $\begin{array}{c}\text { Multivariable } \\
\text { HR* } \\
(95 \% \mathrm{CI})\end{array}$ & $P$ value & $\begin{array}{c}\text { Univariable HR } \\
(95 \% \mathrm{CI})\end{array}$ & $P$ value & $\begin{array}{c}\text { Multivariable } \\
\text { HR* } \\
(95 \% \mathrm{CI})\end{array}$ & \\
\hline Country & & $<0.001$ & & & & 0.409 & & \\
\hline China & 1 & & & & 1 & & & \\
\hline Korea & $0.37[0.33-0.42]$ & & & & $0.89[0.68-1.17]$ & & & \\
\hline Gender & & $<0.001$ & & 0.011 & & 0.125 & & \\
\hline Male & 1 & & 1 & & 1 & & & \\
\hline Female & $0.75[0.66-0.85]$ & & $0.85[0.74-0.96]$ & & $1.25[0.94-1.66]$ & & & \\
\hline Age (yrs) & & $<0.001$ & & $<0.001$ & & 0.118 & & \\
\hline$<60$ & 1 & & 1 & & 1 & & & \\
\hline$\geq 60$ & $1.48[1.32-1.66]$ & & $1.50[1.33-1.68]$ & & $0.80[0.60-1.06]$ & & & \\
\hline Tumor location & & $<0.001$ & & & & 0.676 & & \\
\hline Upper third & 1 & & & & 1 & & & \\
\hline Middle third & $0.57[0.48-0.68]$ & $<0.001$ & & & $0.95[0.64-1.42]$ & 0.794 & & \\
\hline Lower third & $0.66[0.57-0.76]$ & $<0.001$ & & & $0.83[0.59-1.18]$ & 0.309 & & \\
\hline Whole stomach & $3.29[1.92-5.63]$ & $<0.001$ & & & $1.07[0.57-2.02]$ & 0.839 & & \\
\hline Differentiation & & $<0.001$ & & & & 0.069 & & \\
\hline G1 & 1 & & & & 1 & & & \\
\hline G2 & $2.78[2.04-3.79]$ & $<0.001$ & & & $3.58[0.48-26.58]$ & 0.212 & & \\
\hline G3 & $3.66[2.73-4.91]$ & $<0.001$ & & & $5.20[0.73-37.16]$ & 0.101 & & \\
\hline Tumor size (cm) & & $<0.001$ & & & & $<0.001$ & & $<0.001$ \\
\hline$\leq 2$ & 1 & & & & 1 & & 1 & \\
\hline$\sim 5.0$ & $3.30[2.69-4.06]$ & $<0.001$ & & & $1.08[0.43-2.72]$ & 0.869 & $1.12[0.45-2.82]$ & 0.810 \\
\hline$\sim 8.0$ & $7.70[6.23-9.52]$ & $<0.001$ & & & $1.93[0.78-4.77]$ & 0.152 & $1.90[0.77-4.70]$ & 0.163 \\
\hline$>8.0$ & $12.28[9.65-15.63]$ & $<0.001$ & & & $2.65[1.06-6.62]$ & 0.036 & $2.64[1.06-6.58]$ & 0.038 \\
\hline Depth of infiltration (pT) & & $<0.001$ & & $<0.001$ & & 0.188 & & \\
\hline pT1 & 1 & & 1 & & 1 & & & \\
\hline pT2 & $3.56[2.80-4.52]$ & $<0.001$ & $2.89[2.23-3.74]$ & $<0.001$ & $8.37[0.87-80.81]$ & 0.066 & & \\
\hline pT3 & $5.51[4.42-6.87]$ & $<0.001$ & $3.60[2.78-4.67]$ & $<0.001$ & $3.08[0.40-23.70]$ & 0.280 & & \\
\hline pT4a & $12.04[10.07-14.38]$ & $<0.001$ & $6.07[4.80-7.66]$ & $<0.001$ & $5.08[0.71-36.36]$ & 0.106 & & \\
\hline pT4b & 23.61 [17.83-31.27] & $<0.001$ & $\begin{array}{c}7.31[5.29- \\
10.10] \\
\end{array}$ & $<0.001$ & $4.74[0.65-34.44]$ & 0.124 & & \\
\hline Nodal status (pN) & & $<0.001$ & & $<0.001$ & & 0.063 & & \\
\hline $\mathrm{pN} 0$ & 1 & & 1 & & 1 & & & \\
\hline $\mathrm{pN} 1$ & $2.65[2.17-3.24]$ & $<0.001$ & $1.49[1.20-1.85]$ & $<0.001$ & $1.12[0.53-2.36]$ & 0.759 & & \\
\hline $\mathrm{pN} 2$ & $4.62[3.86-5.54]$ & $<0.001$ & $2.10[1.70-2.59]$ & $<0.001$ & $0.98[0.46-2.09]$ & 0.958 & & \\
\hline $\mathrm{pN} 3 \mathrm{a}$ & $9.94[8.46-11.68]$ & $<0.001$ & $3.90[3.18-4.77]$ & $<0.001$ & $1.24[0.65-2.37]$ & 0.506 & & \\
\hline $\mathrm{pN} 3 \mathrm{~b}$ & $17.34[14.49-20.75]$ & $<0.001$ & $6.32[5.05-7.90]$ & $<0.001$ & $1.71[0.92-3.19]$ & 0.093 & & \\
\hline
\end{tabular}




\begin{tabular}{|c|c|c|c|c|c|c|c|c|}
\hline Lymphadenectomy & & $<0.001$ & & 0.015 & & 0.288 & & \\
\hline $\mathrm{D} 1 / \mathrm{D} 1+$ & 1 & & 1 & & 1 & & & \\
\hline $\mathrm{D} 2 / \mathrm{D} 2+$ & $1.91[1.70-2.15]$ & & $0.85[0.74-0.97]$ & & $1.17[0.88-1.56]$ & & & \\
\hline Radicality of surgery & & $<0.001$ & & $<0.001$ & & 0.578 & & \\
\hline R0 & 1 & & 1 & & 1 & & & \\
\hline $\mathrm{R} 1 / \mathrm{R} 2$ & $5.00[3.84-6.50]$ & & $1.84[1.40-2.41]$ & & $1.10[0.78-1.56]$ & & & \\
\hline Resection type & & $<0.001$ & & 0.011 & & 0.004 & & \\
\hline Subtotal & 1 & & 1 & & 1 & & & \\
\hline Total & $2.03[1.81-2.29]$ & & $1.17[1.04-1.32]$ & & $1.50[1.14-1.98]$ & & & \\
\hline Chemotherapy & & $<0.001$ & & 0.001 & & 0.002 & & 0.008 \\
\hline No & 1 & & 1 & & 1 & & 1 & \\
\hline Yes & $3.11[2.78-3.49]$ & & $0.79[0.69-0.91]$ & & $0.62[0.46-0.84]$ & & $0.66[0.49-0.90]$ & \\
\hline
\end{tabular}

Abbreviations: HR, hazard ratio.

* forward selection with likelihood ratio.

patients. We performed multivariable analyses to identify the prognostic factors that most influenced survival. After adjustment, country was not a significant independent prognostic factor. Of the factors identified as independent prognostic factors, some are beyond medical control (including gender, age, depth of infiltration, lymph node metastasis, and resection type), whereas other factors are capable of influence by doctors (including lymphadenectomy, radicality of surgery, and chemotherapy). To our knowledge, this is the first study, not only emphasizing the different cancer characteristics between the two countries, but also focusing on the roles of doctor-correctable factors. This is also the first study to directly propose the solutions to improve the treatment of GC in China.

The proportion of early cancers was much lower and the advanced stages were more frequent in Chinese patients. Conversely, nearly $60 \%$ of Korean patients were diagnosed within early stages of GC. Therefore, it is intuitive that the higher proportion of advanced-stage patients contributed to the poorer survival of Chinese patients. Thanks to the national, population-based GC screening program established in Korea in 1999 [10], the percentage of
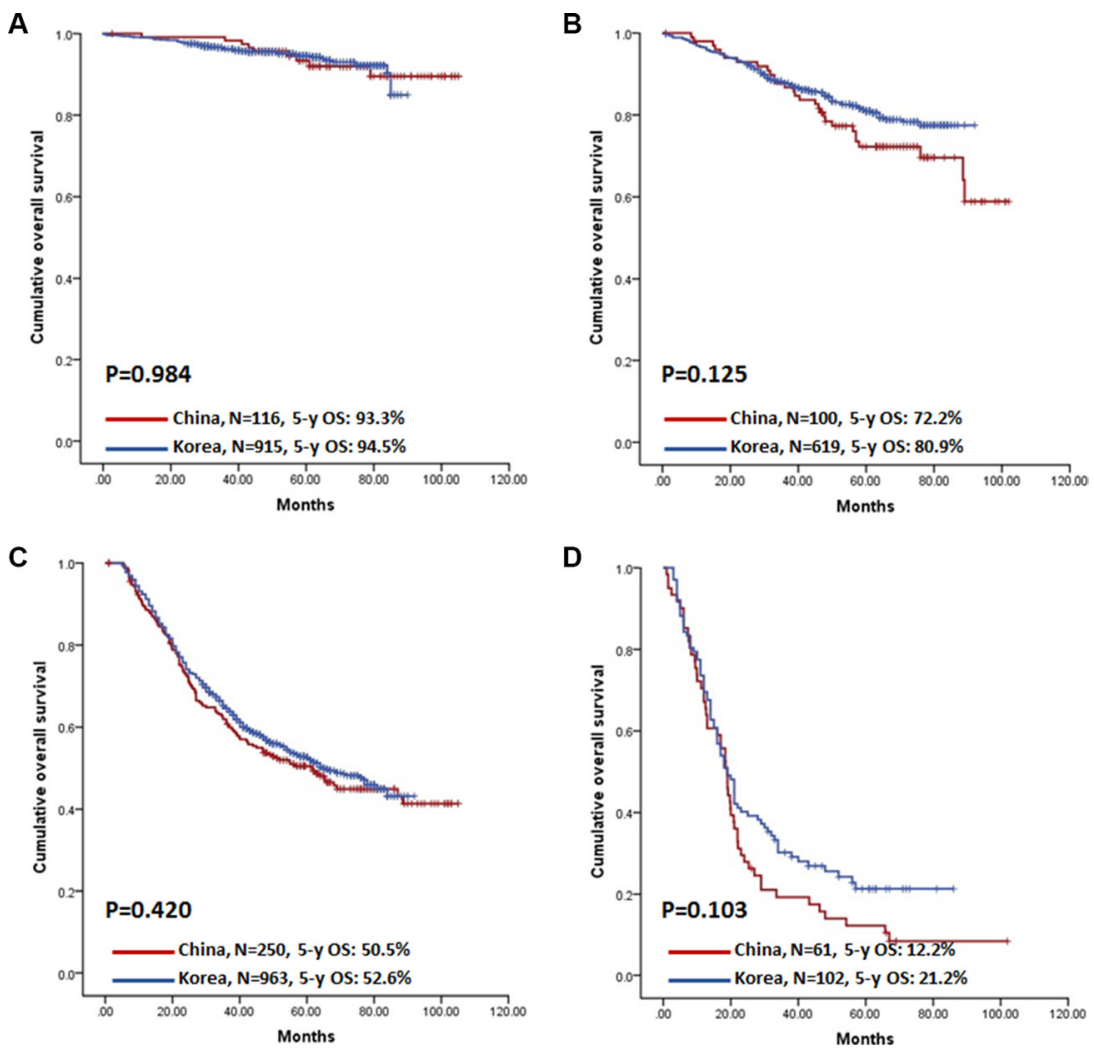

Figure 2: Kaplan-Meier survival analysis of patients with D2 or D2+ lymphadenectomy stratified by stage between China and Korea. (A) Stage I patients; (B) Stage II patients; (C) Stage III patients; (D) Stage IV patients. 
GC diagnosed in early stage has gradually increased from $15 \%$ during $1974-1992$ to $58 \%$ in 2009 [11]. In recent years, despite a slight upward trend of early GC detection in China due to the availability of upper gastrointestinal endoscopy and a shift towards healthconsciousness in China [7, 12,13], the proportion of early GC diagnoses is still low, and advanced GC remains the leading health burden and cause of cancer-related mortality. Fortunately, annual reports indicate that the incidence and mortality of GC has decreased and the mortality-to-prevalence ratio of GC has tended to decline in recent years [11]. These trends have resulted from the China Cancer Prevention and Control Program, a governmental platform dedicated to prevention, screening, and surveillance for cancers (including GC), although there is not a formal, specialized, nationwide cancerscreening program [11]. Establishment of a formal and specialized nationwide screening program for GC will further promote early detection, which will also mitigate the extent of medically-uncontrollable factors that impact survival. In addition, early detection and intervention of the precancerous lesions and eradication of the Helicobacter pylori infection would also contributable [14].

Controversy over lymphadenectomy in GC surgery has persisted for several decades. Several large randomized studies and meta-analyses found that the D2 procedure was significantly associated with postoperative morbidity and mortality, rather than conferring a survival benefit [15-17]. Therefore, limited lymphadenectomy was utilized in a study of GC patients in Western countries [18]. However, not only the prognosis of surgery-only group but also surgery with chemotherapy group from Western trials was significantly poorer compared with that of surgery-only group from Eastern trials where more extensive lymphadenectomy (D2) has been a standard; those difference partly caused by the insufficient lymphadenectomy in Western trials [19-21]. Furthermore, the 15-year follow-up results of a Dutch trial indicate that D2 lymphadenectomy could decrease locoregional recurrence and GC-related death relative to D1 lymphadenectomy [22]. In our study, D2 lymphadenectomy was a positive prognostic factor in stage II and III patients, and D2 lymphadenectomy alone even cured some stage II patients. However, less than $50 \%$ of Chinese patients with stage II and III GC have undergone D2 lymphadenectomy, whereas more than $80 \%$ of Korean patients with the same stage underwent this surgery. This pattern explains why the survival of patients with stage II and III GC was significantly different between these two countries in initial analyses but was similar when the analyses were confined to the patients who underwent D2/ D2+ lymphadenectomy.
A

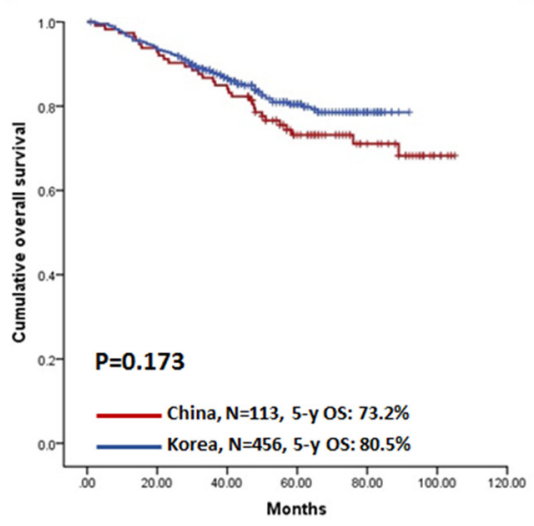

B

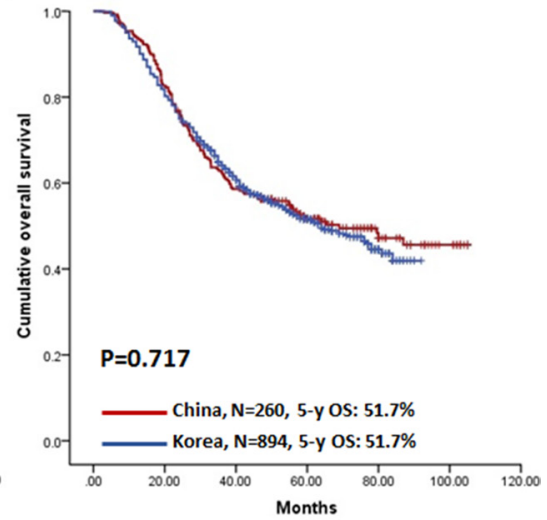

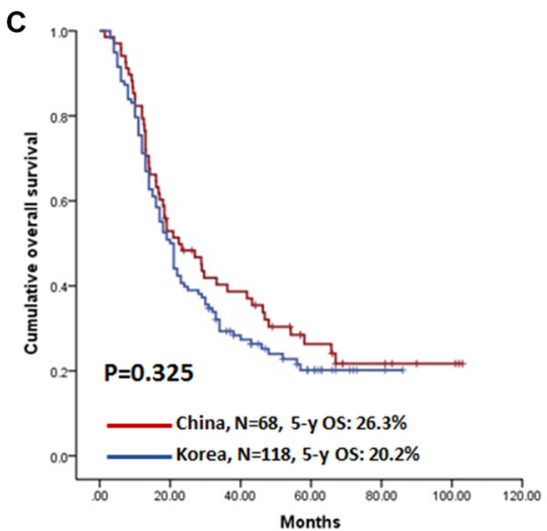

Figure 3: Kaplan-Meier survival analysis of patients with chemotherapy stratified by stage between China and Korea. (A) Stage II patients; (B) Stage III patients; (C) Stage IV patients. 
Table 5: Survival of patients stratified by stages according to lymphadenectomy and chemotherapy in overall population $(N=5982)$

\begin{tabular}{|c|c|c|c|c|c|c|c|c|c|c|c|}
\hline & $\mathbf{N}_{\text {group 1 }}$ & $\stackrel{5-y}{\mathrm{OS}_{\text {group 1 }}}$ & $\mathbf{N}_{\text {group 2 }}$ & $\stackrel{5-y}{\mathrm{OS}_{\text {group 2 }}}$ & $P$ value $\dagger$ & $\begin{array}{l}\text { Unadjusted HR } \\
(95 \% \text { CI) }\end{array}$ & $P$ value & $\begin{array}{c}\text { Adjusted HR } \\
(95 \% \mathrm{CI})^{*}\end{array}$ & $P$ value & $\begin{array}{c}\text { Adjusted HR } \\
(95 \% \text { CI)* for } \\
\text { patients with R0 } \\
\text { resection }\end{array}$ & $P$ value \\
\hline \multicolumn{12}{|c|}{ Without chemotherapy (Group 1) VS with chemotherapy (Group 2) } \\
\hline $\mathrm{I}$ & 3065 & $94.7 \%$ & 84 & $90.4 \%$ & 0.162 & $1.60[0.82-3.11]$ & 0.165 & $1.22[0.54-2.71]$ & 0.635 & $1.34[0.60-2.96]$ & 0.474 \\
\hline II & 419 & $76.4 \%$ & 569 & $78.6 \%$ & 0.404 & $0.89[0.68-1.17]$ & 0.405 & $0.84[0.62-1.14]$ & 0.255 & $0.83[0.61-1.12]$ & 0.226 \\
\hline III & 438 & $40.2 \%$ & 1154 & $51.8 \%$ & $<0.001$ & $0.70[0.60-0.81]$ & $<0.001$ & $0.69[0.59-0.81]$ & $<0.001$ & $0.68[0.57-0.80]$ & $<0.001$ \\
\hline IV & 67 & $7.3 \%$ & 186 & $22.4 \%$ & 0.001 & $0.62[0.45-0.84]$ & 0.002 & $0.60[0.42-0.86]$ & 0.006 & $0.33[0.13-0.87]$ & 0.025 \\
\hline \multicolumn{12}{|c|}{ Group 1 VS Group 2 in D2/D2+ lymphadenectomy group } \\
\hline $\mathrm{I}$ & 993 & $94.3 \%$ & 38 & $92.0 \%$ & 0.983 & $1.01[0.31-3.28]$ & 0.983 & $1.21[0.29-5.00]$ & 0.794 & $1.21[0.29-5.00]$ & 0.794 \\
\hline II & 304 & $80.5 \%$ & 415 & $78.5 \%$ & 0.531 & $1.12[0.79-1.57]$ & 0.532 & $1.05[0.71-1.55]$ & 0.814 & $1.06[0.72-1.56]$ & 0.785 \\
\hline III & 266 & $46.4 \%$ & 947 & $53.9 \%$ & 0.007 & $0.78[0.64-0.94]$ & 0.008 & $0.70[0.57-0.86]$ & 0.001 & $0.69[0.56-0.85]$ & $<0.001$ \\
\hline IV & 33 & $3.0 \%$ & 130 & $21.5 \%$ & 0.003 & $0.55[0.37-0.83]$ & 0.004 & $0.53[0.31-0.91]$ & 0.021 & $-^{\#}$ & $--^{\#}$ \\
\hline \multicolumn{12}{|c|}{ Group 1 VS Group 2 in D1/D1+ lymphadenectomy group } \\
\hline $\mathrm{I}$ & 2072 & $95.0 \%$ & 46 & $89.0 \%$ & 0.060 & $2.14[0.95-4.79]$ & 0.065 & $1.40[0.51-3.87]$ & 0.515 & $1.42[0.52-3.93]$ & 0.497 \\
\hline II & 115 & $65.6 \%$ & 154 & $79.0 \%$ & 0.010 & $0.53[0.33-0.87]$ & 0.011 & $0.51[0.30-0.89]$ & 0.018 & $0.51[0.30-0.89]$ & 0.018 \\
\hline III & 172 & $30.6 \%$ & 207 & $42.7 \%$ & 0.001 & $0.67[0.52-0.86]$ & & $0.60[0.45-0.80]$ & $<0.001$ & $0.60[0.45-0.82]$ & 0.001 \\
\hline IV & 34 & $11.4 \%$ & 56 & $24.0 \%$ & 0.044 & $0.62[0.38-0.99]$ & 0.047 & $0.43[0.24-0.78]$ & 0.005 & $-^{\#}$ & $-^{\#}$ \\
\hline \multicolumn{12}{|c|}{ D1/D1+ (Group 1) VS D2/D2+ lymphadenectomy (Group 2) } \\
\hline $\mathrm{I}$ & 2118 & $94.8 \%$ & 1031 & $94.2 \%$ & 0.323 & $1.18[0.85-1.62]$ & 0.324 & $0.94[0.66-1.34]$ & 0.720 & $0.98[0.68-1.39]$ & 0.888 \\
\hline II & 269 & $73.3 \%$ & 719 & $79.1 \%$ & 0.186 & $0.80[0.60-1.08]$ & 0.146 & $0.78[0.56-1.10]$ & 0.160 & $0.76[0.54-1.07]$ & 0.118 \\
\hline III & 379 & $37.2 \%$ & 1213 & $52.2 \%$ & $<0.001$ & $0.70[0.60-0.81]$ & $<0.001$ & $0.79[0.66-0.95]$ & 0.014 & $0.81[0.67-0.99]$ & 0.040 \\
\hline IV & 90 & $19.3 \%$ & 163 & $17.8 \%$ & 0.283 & $1.17[0.88-1.56]$ & 0.288 & $1.39[0.98-1.97]$ & 0.066 & $2.64[0.96-7.26]$ & 0.060 \\
\hline \multicolumn{12}{|c|}{ Group 1 VS Group 2 in with chemotherapy group } \\
\hline I & 46 & $89.0 \%$ & 38 & $92.0 \%$ & 0.231 & $0.44[0.11-1.74]$ & 0.243 & $\begin{array}{c}0.16[0.015- \\
1.68] \\
\end{array}$ & 0.127 & $0.16[0.015-1.68]$ & 0.127 \\
\hline II & 154 & $79.0 \%$ & 415 & $78.5 \%$ & 0.535 & $1.14[0.75-1.75]$ & 0.535 & $1.07[0.65-1.77]$ & 0.787 & $1.05[0.64-1.74]$ & 0.837 \\
\hline III & 207 & $42.7 \%$ & 947 & $53.9 \%$ & 0.022 & $0.79[0.64-0.97]$ & 0.023 & $0.73[0.57-0.93]$ & 0.011 & $0.74[0.57-0.97]$ & 0.025 \\
\hline IV & 56 & $24.0 \%$ & 130 & $21.5 \%$ & 0.291 & $1.22[0.84-1.75]$ & 0.296 & $1.07[0.68-1.69]$ & 0.763 & $-^{\#}$ & $-^{\#}$ \\
\hline \multicolumn{12}{|c|}{ Group 1 VS Group 2 in without chemotherapy group } \\
\hline $\mathrm{I}$ & 2072 & $95.0 \%$ & 993 & $94.3 \%$ & 0.196 & $1.24[0.89-1.72]$ & 0.197 & $0.95[0.66-1.37]$ & 0.786 & $0.98[0.68-1.41]$ & 0.900 \\
\hline II & 115 & $65.6 \%$ & 304 & $80.5 \%$ & 0.004 & $0.54[0.35-0.81]$ & 0.003 & $0.56[0.34-0.93]$ & 0.023 & $0.56[0.34-0.93]$ & 0.023 \\
\hline III & 172 & $30.6 \%$ & 266 & $46.4 \%$ & 0.002 & $0.69[0.54-0.88]$ & 0.002 & $0.67[0.48-0.93]$ & 0.016 & $0.69[0.50-0.95]$ & 0.025 \\
\hline IV & 34 & $11.4 \%$ & 33 & $3.0 \%$ & 0.068 & $1.59[0.96-2.64]$ & 0.074 & $1.79[0.96-3.34]$ & 0.069 & $-^{\#}$ & $-^{\#}$ \\
\hline
\end{tabular}

Abbreviations: N, number; OS, overall survival; HR, hazard ratio.

Note: The values of group 1 were regarded as references for the HR analyses.

t $p$-value for log-rank test.

*Adjust for country, gender, age, surgical methods, tumor location, differentiation, tumor size, $\mathrm{T}$ stage, $\mathrm{N}$ stage, resection type, lymphadenectomy, radicality of surgery, chemotherapy.

\#The valid sample size is too small to calculate the adjust HR.

In the past two decades, the Chinese anti-cancer association/Gastric Cancer Association have promoted a program of itinerant lectures on standard GC operation. Due to efforts to spread training for D2 lymphadenectomy in China, GC surgery has become more standardized in recent years. Our published data demonstrate that the proportion of D2/D2+ lymphadenectomy from 2000 to 2005 was approximately $10 \%$ but increased to nearly $40 \%$ after 2006, an expansion that was accompanied by an increase in the number of harvested lymph nodes and improved OS [7], demonstrating the survival benefit brought by $\mathrm{D} 2$ lymphadenectomy.

For safety reasons, Western guidelines recommend the performance of D2 surgery only in high-volume centres by experienced surgeons [23, 24]. Because the present results were from two large volume hospitals in two countries, there was no significant differences in morbidity and mortality even after D2 lymphadenectomy. However, it has been widely reported that D2 lymphadenectomy can be routinely performed with low morbidity and mortality 
Table 6: Proportion of patients who received different treatment (lymphadenectomy and/or chemotherapy) according to each stage in two different countries

\begin{tabular}{|c|c|c|c|c|c|c|c|c|}
\hline & \multicolumn{4}{|c|}{ China } & \multicolumn{4}{|c|}{ Korea } \\
\hline & $\begin{array}{c}\text { Total } \\
\text { number of } \\
\text { patients }\end{array}$ & $\begin{array}{c}\text { Number } \\
\text { of Patients } \\
\text { with D2/ } \\
\text { D2+ (\%) }\end{array}$ & $\begin{array}{c}\text { Number of } \\
\text { Patients with } \\
\text { chemotherapy (\%) }\end{array}$ & $\begin{array}{c}\text { Number of } \\
\text { Patients with } \\
\text { D2/D2+ and } \\
\text { chemotherapy }(\%)\end{array}$ & $\begin{array}{c}\text { Total } \\
\text { number } \\
\text { of } \\
\text { patients }\end{array}$ & $\begin{array}{c}\text { Number of } \\
\text { Patients with } \\
\text { D2/D2+ (\%) }\end{array}$ & $\begin{array}{c}\text { Number of } \\
\text { Patients with } \\
\text { chemotherapy }(\%)\end{array}$ & $\begin{array}{l}\text { Number of Patients } \\
\text { with D2/D2+ and } \\
\text { chemotherapy (\%) }\end{array}$ \\
\hline Stage I & 281 & $149(53.0)$ & $82(29.2)$ & $39(13.9)$ & 2931 & $917(31.3)$ & $13(0.4)$ & $5(0.2)$ \\
\hline Stage II & 264 & $130(49.2)$ & $131(49.6)$ & $58(22.0)$ & 797 & $640(80.3)$ & $456(57.2)$ & $367(46.0)$ \\
\hline Stage III & 676 & $325(48.1)$ & $298(44.1)$ & $141(20.9)$ & 1109 & $1021(92.1)$ & $904(81.5)$ & $836(75.4)$ \\
\hline Stage IV & 144 & $72(50.0)$ & $76(52.8)$ & $36(25.0)$ & 144 & $109(75.7)$ & $122(84.7)$ & $96(66.7)$ \\
\hline
\end{tabular}

in small-volume hospitals $[17,25,26]$. Therefore, there is no longer a sustainable argument against standard D2 gastrectomy in modern surgery for invasive GC, especially given the poor results of para-aortic lymphadenectomy from the JCOG 9501 trial $[23,27,28]$. Nonetheless, the training necessary for D2 gastrectomy and the quality of performance remain challenges need to be addressed.

Despite the receipt of D2 lymphadenectomy for resectable GC, about $40 \%$ of patients relapsed within three years of surgery [21, 27]. Therefore, various adjuvant treatment modalities have been investigated to reduce postoperative recurrence, with some Western clinical trials yielding favourable results $[19,20]$. However, these results should be interpreted and applied cautiously to East
Asian patients because lymphadenectomy in these studies was limited, and the results tended to vary by geographic region [29]. Two large randomized controlled trials in Asia (ACTS-GC trial and CLASSIC trial) have established the benefit role of adjuvant chemotherapy in stage II or III GC patients after D2 gastrectomy $[21,30]$.

In accordance with previous studies, our results demonstrate that chemotherapy can improve the prognosis of patients with stage III GC, even partly compensating for the absence of D2 lymphadenectomy in patients with stage II GC [19-21, 30]. In addition, adjuvant chemotherapy increased the OS of patients with distant metastasis. The proportion of stage III or IV patients receiving adjuvant therapy-those most likely to benefit from the addition
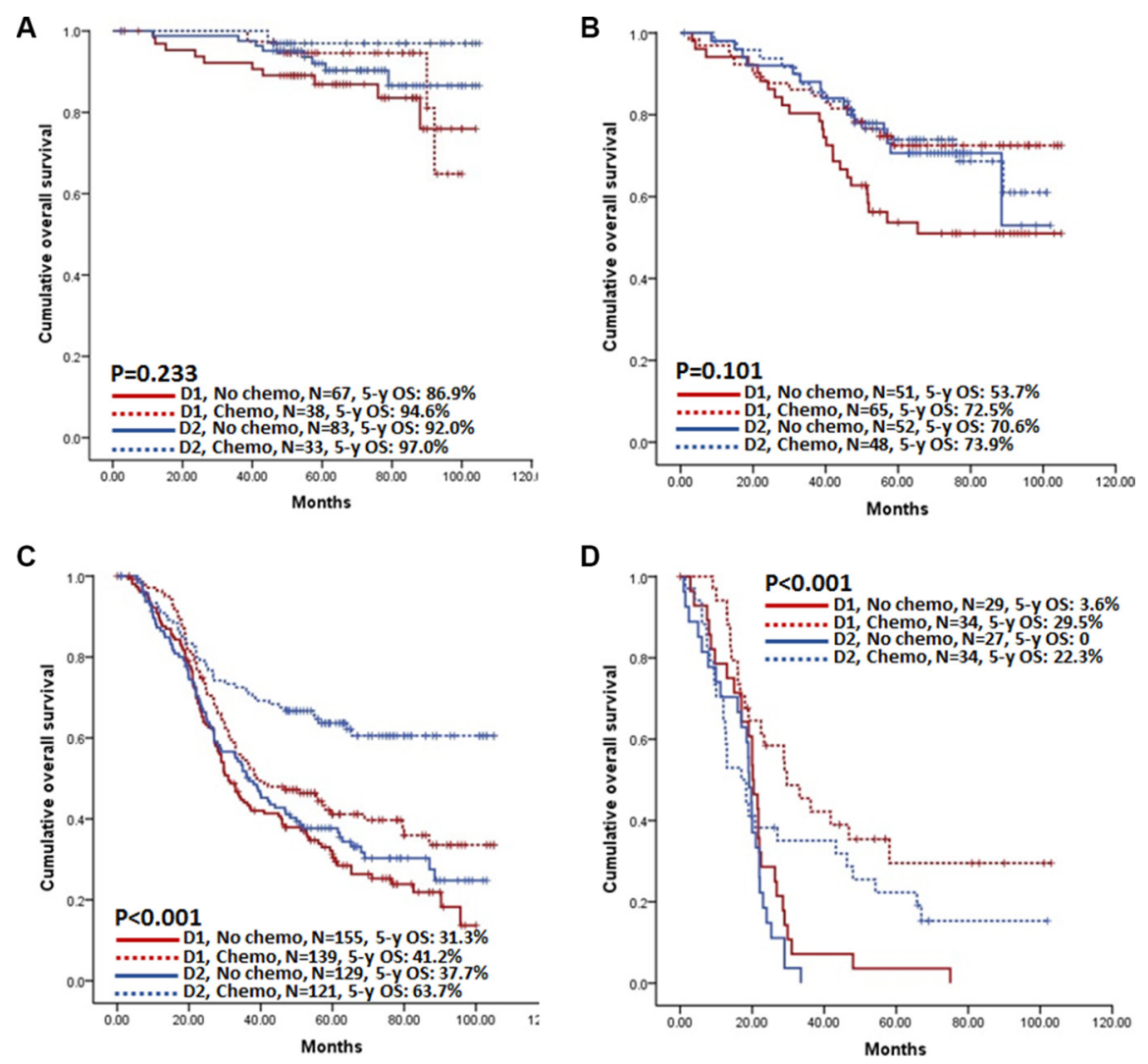

Figure 4: Kaplan-Meier survival analysis of Chinese patients according to the treatment type in each stage. (A) Stage I patients; (B) Stage II patients; (C) Stage III patients; (D) Stage IV patients. 
Table 7: Multivariable cox-proportional hazard regression analysis in Chinese population $(N=1105)$

\begin{tabular}{|c|c|c|c|c|c|}
\hline \multicolumn{3}{|c|}{ M0 patients $(N=981)$} & \multicolumn{3}{|c|}{ M1 patients $(N=124)$} \\
\hline & $\begin{array}{c}\text { Multivariable } \\
\text { HR }^{*}\end{array}$ & $P$ value & & $\begin{array}{c}\text { Multivariable } \\
\text { HR }^{\dagger}\end{array}$ & $P$ value \\
\hline Treatment & & $<0.001$ & Treatment & & 0.001 \\
\hline D1/D1+ without chemotherapy & 1 & & D1/D1+ without chemotherapy & 1 & \\
\hline D1/D1+ with chemotherapy & $0.63[0.49-0.81]$ & $<0.001$ & D1/D1+ with chemotherapy & $0.45[0.25-0.79]$ & 0.006 \\
\hline D2/D2+ without chemotherapy & $0.86[0.67-1.11]$ & 0.244 & D2/D2+ without chemotherapy & $1.53[0.88-2.63]$ & 0.129 \\
\hline D2/D2+ with chemotherapy & $0.44[0.32-0.59]$ & $<0.001$ & D2/D2+ with chemotherapy & $0.91[0.53-1.57]$ & 0.732 \\
\hline Radicality of surgery & & 0.001 & Tumor size (cm) & & 0.005 \\
\hline $\mathrm{R} 0$ & 1 & & $\leq 2$ & 1 & \\
\hline $\mathrm{R} 1 / \mathrm{R} 2$ & $1.97[1.30-2.99]$ & & $\sim 5.0$ & $3.43[0.46-25.78]$ & 0.232 \\
\hline Depth of infiltration (pT) & & $<0.001$ & $\sim 8.0$ & $5.81[0.78-43.40]$ & 0.087 \\
\hline pT1 & 1 & & $>8.0$ & $7.73[1.02-58.64]$ & 0.048 \\
\hline pT2 & $2.28[1.32-3.95]$ & 0.003 & & & \\
\hline pT3 & $3.31[1.84-5.94]$ & $<0.001$ & & & \\
\hline pT4a & $3.80[2.34-6.18]$ & $<0.001$ & & & \\
\hline pT4b & 4.18 [2.39-7.32] & $<0.001$ & & & \\
\hline Nodal status (pN) & & $<0.001$ & & & \\
\hline $\mathrm{pN} 0$ & 1 & & & & \\
\hline $\mathrm{pN} 1$ & $1.82[1.28-2.59]$ & 0.001 & & & \\
\hline $\mathrm{pN} 2$ & $1.80[1.26-2.57]$ & 0.001 & & & \\
\hline $\mathrm{pN} 3 \mathrm{a}$ & $3.92[2.83-5.43]$ & $<0.001$ & & & \\
\hline $\mathrm{pN} 3 \mathrm{~b}$ & $5.25[3.64-7.57]$ & $<0.001$ & & & \\
\hline
\end{tabular}

Abbreviations: HR, hazard ratio.

*forward selection (likelihood ratio) with treatment type, gender, age, surgical methods, tumor location, differentiation, tumor size, $\mathrm{T}$ stage, $\mathrm{N}$ stage, resection type, radicality of surgery.

forward selection (likelihood ratio) with treatment type, gender, age, surgical methods, tumor location, differentiation, tumor size, T stage, $\mathrm{N}$ stage, $\mathrm{M}$ stage, resection type, radicality of surgery.

of chemotherapy-was considerably smaller in China than in Korea. Several factors may account for this. We included patients from 2006 to 2010 in this study, but little evidence supporting the application of adjuvant therapy after D2 surgery occurred during that time. Therefore, some patients with curative surgery did not wish to receive chemotherapy because of the risk of toxic effects [29]. This is also true for Korean patients with stage II GC; low compliance of patients from both countries contributes to this phenomenon. Future attention should be paid in China to the spread of and education about chemotherapy, the invention of new drugs or regimens with lower toxicity, and the appropriate application of chemotherapy. With respect to lymphadenectomy and chemotherapy, factors controllable in clinical practice, only $20 \%$ of stage II-IV patients were given D2 lymphadenectomy and adjuvant chemotherapy although they account for nearly $80 \%$ of GC cases in China. In our study, both D2/D2+ and chemotherapy were selected as independent prognostic factors, and the best prognosis appeared in the patients treated by $\mathrm{D} 2 / \mathrm{D} 2+$ with chemotherapy; if the proportion of patients with D2 lymphadenectomy and adjuvant chemotherapy increases, long-term survival will improve.

There are some limitations of this study. Firstly, selection bias, detection bias, and performance of analysis bias are possible in any retrospective study [31]. Secondly, our data are from only two institutions, one Chinese and one Korean; therefore, the data may not represent the general population well. However, the numbers of GC 
surgeries performed in these two institutions are large, and the patients' origins cover large areas of China and Korea, which may serve as representative for two large populations. Thirdly, our study was confined to cases with gastrectomy, excluding patients who underwent nonresectional surgery.

In conclusion, many differences in tumour characteristics exist between these two countries. A high percentage of patients diagnosed GC in early stages and standardized treatment in Korea contributes to better survival than China. To improve survival outcomes in China, the promotion of an early screening program, training and spread of standard D2 lymphadenectomy, and appropriate applications of chemotherapy are necessary.

\section{MATERIALS AND METHODS}

\section{Patients}

This study consisted of 6346 GC patients, 1365 Chinese and 4981 Korean, diagnosed between January 2006 and December 2010. Data were extracted from the databases of West China Hospital, Sichuan University, and Severance Hospital, Yonsei University Health System, and analysed retrospectively (Figure 5). The diagnosis

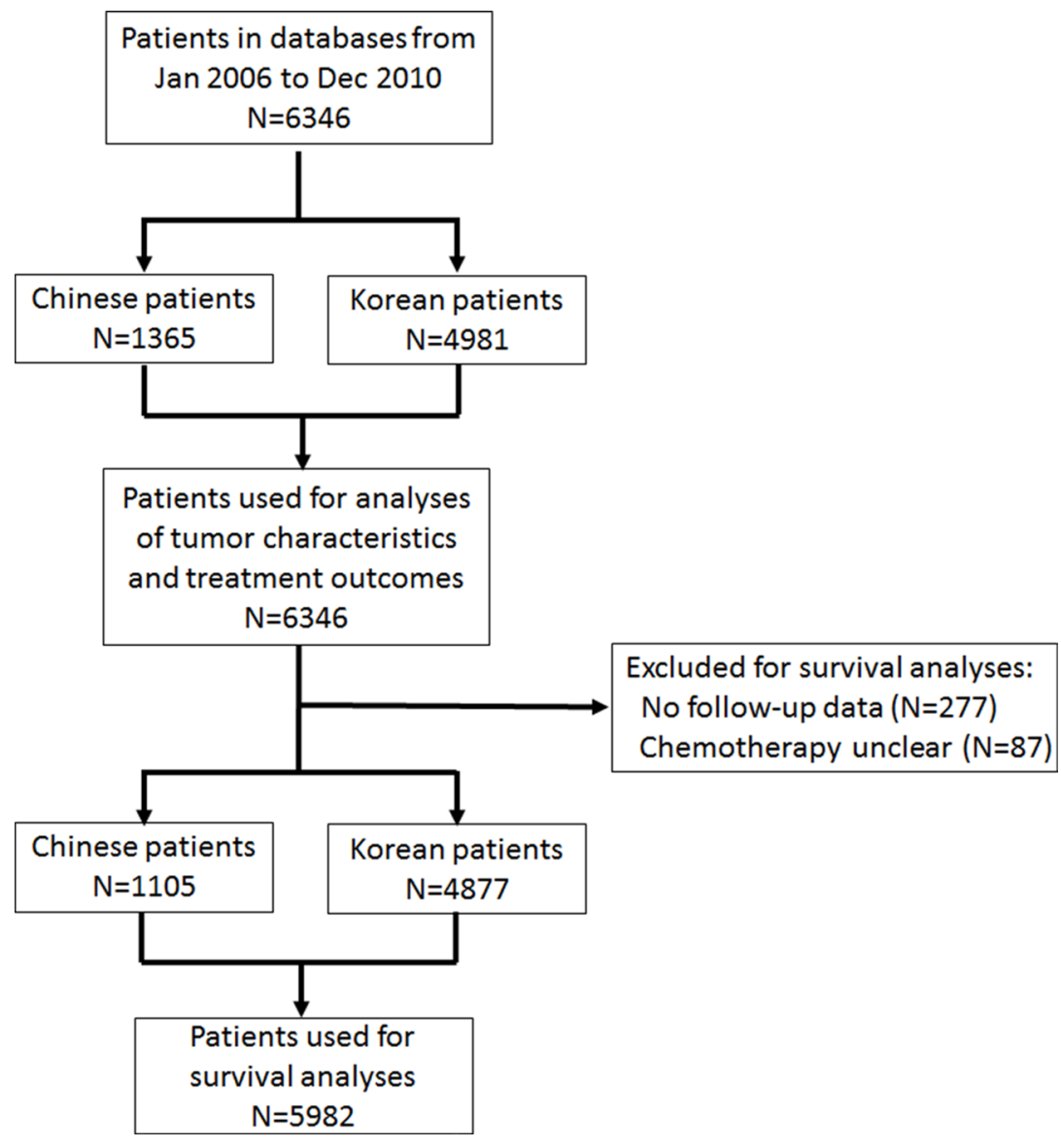

xcluded for survival analyses:

( $=87)$
No follow-up data $(\mathrm{N}=277)$ of gastric adenocarcinoma for all patients was confirmed by upper endoscopy and biopsy. Inclusion criteria were the following: all cases of early and advanced GC, both curative and palliative gastrectomies, and patients with total or subtotal gastrectomies. Non-resectional surgeries, however, such as bypass surgery, gastrostomy, or jejunostomy, were excluded. Patients with other gastric pathologies, such as lymphoma, gastrointestinal stromal tumour or adenosquamous carcinoma, previous malignancies, remnant GC, or those treated by wedge resection or endoscopic resection were also excluded. The West China Hospital Research Ethics Committee and Institutional Review Board of Severance Hospital, Yonsei University Health System, approved retrospective analyses of anonymous data (4-2015-0647). Signed patient informed consent was waived because of the retrospective nature of the analysis.

\section{Treatments}

All patients underwent gastrectomy with D1, D1+, D2, or D2+ lymphadenectomy for GC as defined by the Japanese Classification of Gastric Carcinoma [32]. Total or subtotal gastrectomy was performed according to the location of the primary lesion. Billroth I, Billroth II, or

Figure 5: Flow chart showing selection procedure of patients. 
Roux-en-Y anastomosis with hand-sewn or mechanical staples was performed to reconstruct the digestive tract after distal gastrectomy. Esophagogastric anastomosis was used after proximal gastrectomy, and Roux-en-Y esophagojejunostomy was utilized for total gastrectomy. Chemotherapy treatments consisted of fluoropyrimidine alone or a fluoropyrimidine/platinum-based regimen.

\section{Outcomes measurements}

Clinicopathologic features, treatment outcomes, morbidity and mortality (according to the ClavienDindo Classification), and overall survival (OS) were compared [33]. Patients underwent follow-ups conducted by telephone calls, letters, or outpatient visits. Survival status at the last follow-up for Korean patients was also based on data registered with the Korean National Cancer Center. The follow-up information was updated in December 2014 for Chinese patients and March 2014 for Korean patients. The overall follow-up rate was $95.6 \%(6069 / 6346)$. OS was calculated from the date of operation until the date of death or the last follow-up. The mean follow-up duration was $69.3 \pm 20.3$ months in Chinese patients and $56.2 \pm 16.9$ in Korean patients. All terminologies were based on the Japanese Classification of Gastric Carcinoma [34].

\section{Statistical analysis}

The assumption of normality for continuous variables was assessed by the Kolmogorov-Smirnov test. All data are reported as mean \pm standard deviation for continuous variable or frequency (percentage) for categorical variables. An independent two-sample t-test, Pearson's chi-square test (or Fisher's exact test), or Spearman's test were used to compare differences between the two countries, as appropriate. Survival rates were calculated by Kaplan-Meier estimator and compared by the log-rank test. Univariable or multivariable Cox proportional hazards regression models were used to identify independent prognostic factors. Variables included in multivariable models were selected by the forward method with likelihood ratio (two-tailed $p \leq 0.05)$. Two-tailed $p$-values of less than 0.05 were considered statistically significant. Statistical analyses were performed by using SPSS 19.0 software (SPSS, Chicago, IL, USA).

\section{ACKNOWLEDGMENTS}

This work was internal supported by the Volunteer Team of Gastric Cancer Surgery (VOLTGA), West China Hospital, Sichuan University, P.R. China.

\section{FUNDING}

(1) National Natural Science Foundation of China (No.81301867, 81372344); (2) Sichuan Province Youth Science \& Technology Innovative Research Team (No.2015TD0009); (3) This research was supported by a grant of the National R\&D Program for Cancer Control, Ministry of Health and Welfare, Republic of Korea (1020390, 1320360).

\section{CONFLICTS OF INTEREST}

No potential conflicts of interest were disclosed.

\section{REFERENCES}

1. Torre LA, Bray F, Siegel RL, Ferlay J, Lortet-Tieulent J, Jemal A. Global cancer statistics, 2012. CA Cancer J Clin. 2015; 65:87-108.

2. Chen W, Zheng R, Zeng H, Zhang S, He J. Annual report on status of cancer in China, 2011. Chin J Cancer Res. 2015; 27:2-12.

3. Jung KW, Won YJ, Kong HJ, Oh CM, Cho H, Lee DH, Lee KH. Cancer statistics in Korea: incidence, mortality, survival, and prevalence in 2012. Cancer Res Treat. 2015; 47:127-141.

4. Strong VE, Song KY, Park CH, Jacks LM, Gonen M, Shah M, Coit DG, Brennan MF. Comparison of gastric cancer survival following R0 resection in the United States and Korea using an internationally validated nomogram. Ann Surg. 2010; 251:640-646.

5. Verdecchia A, Mariotto A, Gatta G, Bustamante-Teixeira MT, Ajiki W. Comparison of stomach cancer incidence and survival in four continents. Eur J Cancer. 2003; 39:1603-1609.

6. Siegel RL, Miller KD, Jemal A. Cancer statistics, 2015. CA Cancer J Clin. 2015; 65:5-29.

7. Zhang WH, Chen XZ, Liu K, Chen XL, Yang K, Zhang B, Chen ZX, Chen JP, Zhou ZG, Hu JK. Outcomes of surgical treatment for gastric cancer patients: 11-year experience of a Chinese high-volume hospital. Med Oncol. 2014; 31:150.

8. Gill S, Shah A, Le N, Cook EF, Yoshida EM. Asian ethnicity-related differences in gastric cancer presentation and outcome among patients treated at a canadian cancer center. J Clin Oncol. 2003; 21:2070-2076.

9. Redaniel MT, Laudico A, Mirasol-Lumague MR, Gondos A, Pulte D, Mapua C, Brenner H. Cancer survival discrepancies in developed and developing countries: comparisons between the Philippines and the United States. Br J Cancer. 2009; 100:858-862.

10. Suh M, Choi KS, Park B, Lee YY, Jun JK, Lee DH, Kim Y. Trends in Cancer Screening Rates among Korean Men and 
Women: Results of the Korean National Cancer Screening Survey, 2004-2013. Cancer Res Treat. 2016; 48:1-10.

11. Chen XZ, Zhang WH, Hu JK. A difficulty in improving population survival outcome of gastric cancer in mainland China: low proportion of early diseases. Med Oncol. 2014; $31: 315$.

12. Leung WK, Wu MS, Kakugawa Y, Kim JJ, Yeoh KG, Goh KL, Wu KC, Wu DC, Sollano J, Kachintorn U, Gotoda T, Lin JT, You WC, et al. Asia Pacific Working Group on Gastric Cancer. Screening for gastric cancer in Asia: current evidence and practice. Lancet Oncol. 2008; 9:279-287.

13. Liu K, Yang K, Zhang W, Chen X, Chen X, Zhang B, Chen Z, Chen J, Zhao Y, Zhou Z, Chen L, Hu J. Changes of Esophagogastric Junctional Adenocarcinoma and Gastroesophageal Reflux Disease Among Surgical Patients During 1988-2012: A Single-Institution, High-Volume Experience in China. Ann Surg. 2016; 263:88-95.

14. Amedei A, Munari F, Bella CD, Niccolai E, Benagiano M, Bencini L, Cianchi F, Farsi M, Emmi G, Zanotti G, de Bernard M, Kundu M, D’Elios MM. Helicobacter pylori secreted peptidyl prolyl cis, trans-isomerase drives Th17 inflammation in gastric adenocarcinoma. Intern Emerg Med. 2014; 9:303-309.

15. Cuschieri A, Fayers P, Fielding J, Craven J, Bancewicz J, Joypaul V, Cook P. Postoperative morbidity and mortality after D1 and D2 resections for gastric cancer: preliminary results of the MRC randomised controlled surgical trial. The Surgical Cooperative Group. Lancet. 1996; 347:995-999.

16. Hartgrink HH, van de Velde CJ, Putter H, Bonenkamp JJ, Klein Kranenbarg E, Songun I, Welvaart K, van Krieken JH, Meijer S, Plukker JT, van Elk PJ, Obertop H, Gouma DJ, et al. Extended lymph node dissection for gastric cancer: who may benefit? Final results of the randomized Dutch gastric cancer group trial. J Clin Oncol. 2004; 22:2069-2077.

17. Memon MA, Subramanya MS, Khan S, Hossain MB, Osland E, Memon B. Meta-analysis of D1 versus D2 gastrectomy for gastric adenocarcinoma. Ann Surg. 2011; 253:900-911.

18. Yoon SS, Yang HK. Lymphadenectomy for gastric adenocarcinoma: should west meet east? Oncologist. 2009; 14:871-882.

19. Macdonald JS, Smalley SR, Benedetti J, Hundahl SA, Estes NC, Stemmermann GN, Haller DG, Ajani JA, Gunderson LL, Jessup JM, Martenson JA. Chemoradiotherapy after surgery compared with surgery alone for adenocarcinoma of the stomach or gastroesophageal junction. N Engl J Med. 2001; 345:725-730.

20. Cunningham D, Allum WH, Stenning SP, Thompson JN, Van de Velde CJ, Nicolson M, Scarffe JH, Lofts FJ, Falk SJ, Iveson TJ, Smith DB, Langley RE, Verma M, et al. MAGIC Trial Participants. Perioperative chemotherapy versus surgery alone for resectable gastroesophageal cancer. N Engl J Med. 2006; 355:11-20.
21. Noh SH, Park SR, Yang HK, Chung HC, Chung IJ, Kim SW, Kim HH, Choi JH, Kim HK, Yu W, Lee JI, Shin DB, Ji J, et al. CLASSIC trial investigators. Adjuvant capecitabine plus oxaliplatin for gastric cancer after D2 gastrectomy (CLASSIC): 5-year follow-up of an open-label, randomised phase 3 trial. Lancet Oncol. 2014; 15:1389-1396.

22. Songun I, Putter H, Kranenbarg EM, Sasako M, van de Velde CJ. Surgical treatment of gastric cancer: 15-year follow-up results of the randomised nationwide Dutch D1D2 trial. Lancet Oncol. 2010; 11:439-449.

23. National Comprehensive Cancer Network. NCCN Clinical Practice Guidelines in Oncology ( $\mathrm{NCCN}$ guidelines $\left.{ }^{\circledR}\right)$ Gastric Cancer Version3.2015. http://www.ncen.org/ professionals/physician_gls/PDF/gastric.pdf. (accessed April 15, 2015).

24. Waddell T, Verheij M, Allum W, Cunningham D, Cervantes A, Arnold D; European Society for Medical Oncology (ESMO); European Society of Surgical Oncology (ESSO); European Society of Radiotherapy and Oncology (ESTRO). Gastric cancer: ESMO-ESSO-ESTRO Clinical Practice Guidelines for diagnosis, treatment and follow-up. Ann Oncol. 2013; 24:vi57-vi63.

25. Parikh D, Johnson M, Chagla L, Lowe D, McCulloch P. D2 gastrectomy: lessons from a prospective audit of the learning curve. Br J Surg. 1996; 83:1595-1599.

26. Kim CY, Nam BH, Cho GS, Hyung WJ, Kim MC, Lee HJ, Ryu KW, Ryu SW, Shin DW, Lee JH. Learning curve for gastric cancer surgery based on actual survival. Gastric Cancer. 2016; 19:631-638.

27. Sasako M, Sano T, Yamamoto S, Kurokawa Y, Nashimoto A, Kurita A, Hiratsuka M, Tsujinaka T, Kinoshita T, Arai K, Yamamura Y, Okajima K; Japan Clinical Oncology Group. D2 lymphadenectomy alone or with para-aortic nodal dissection for gastric cancer. N Engl J Med. 2008; 359:453-462.

28. Japanese gastric cancer association. Japanese gastric cancer treatment guidelines 2010 (ver. 3). Gastric Cancer. 2011; 14:113-123.

29. Bang YJ, Kim YW, Yang HK, Chung HC, Park YK, Lee KH, Lee KW, Kim YH, Noh SI, Cho JY, Mok YJ, Kim YH, Ji J, et al. CLASSIC trial investigators. Adjuvant capecitabine and oxaliplatin for gastric cancer after D2 gastrectomy (CLASSIC): a phase 3 open-label, randomised controlled trial. Lancet. 2012; 379:315-321.

30. Sakuramoto S, Sasako M, Yamaguchi T, Kinoshita T, Fujii M, Nashimoto A, Furukawa H, Nakajima T, Ohashi Y, Imamura H, Higashino M, Yamamura Y, Kurita A, et al. ACTS-GC Group. Adjuvant chemotherapy for gastric cancer with S-1, an oral fluoropyrimidine. N Engl J Med. 2007; 357:1810-1820.

31. Yang K, Zhang WH, Chen XZ, Chen XL, Zhang B, Chen ZX, Zhou ZG, Hu JK. Survival benefit and safety of no. 10 lymphadenectomy for gastric cancer patients with total gastrectomy. Medicine (Baltimore). 2014; 93:e158. 
32. Japanese Gastric Cancer Association. Japanese Classification of Gastric Carcinoma - 2nd English Edition -. Gastric Cancer. 1998; 1:10-24.

33. Clavien PA, Barkun J, de Oliveira ML, Vauthey JN, Dindo D, Schulick RD, de Santibañes E, Pekolj J, Slankamenac K, Bassi C, Graf R, Vonlanthen R, Padbury R, et al. The
Clavien-Dindo classification of surgical complications: fiveyear experience. Ann Surg. 2009; 250:187-196.

34. Japanese gastric cancer association. Japanese classification of gastric carcinoma: 3rd English version. Gastric Cancer. 2011; 14:101-112. 